\title{
Research on the Teaching Design and Experiment in Physics Education at a Junior High School Based on STEAM Education and 6E Learning Process
}

\author{
Li An \\ Physics Department, Taiyuan Normal University \\ Jin Zhong, China
}

\author{
Jin-Wen Yang \\ Physics Department, Taiyuan Normal University \\ Jin Zhong, China
}

\begin{abstract}
STEAM education is being studied by educators in many countries and this work was designed to explore the validity application of STEAM education in physics teaching at junior high school in China through using two methods which were case studies and experimental studies. The teaching case was designed creatively in case studies by choosing the core concept "harmful noise"in Acoustics as an example, designing and implementing technology application with the solving engineering problems, and the learning process of "engage, explore, explain, engineer, extend and evaluate".And there were 112 students attended this work for three months in experimental studies.Hence, through using questionnaire survey and teacher evaluation we expect the results of this study can effectively promotes and develops the students' physics core literacy and the effects of physics teaching.
\end{abstract}

Keywords-STEAM education; $6 E$ design learning process; noise reduction device; coreliteracy;physics curriculum

\section{INTRODUCTION}

STEAM education focuses on an adopting integrated approach to guide students to actively construct the relationship between science, technology, engineering, art and mathematics. Except for comprehensive thinking and interdisciplinary learning, the nature characteristics of STEAM teaching also emphasizes the combination of theory and practice, and also has the output of finished products. "Physics Curriculum Standards for Compulsory Education(2011 Edition)"was promulgated in recent years in China, it proposes:Pay attention to the connection from knowledge to production, its using in reality life and the using in the development times.That is to say, the teachers should consciously let students to understand the development of production and knowledge, and knowledge is come from production, and science as a whole discipline is connect with other disciplines, and learn the impact of science and technology on humans ${ }^{[1]}$. The introduction of the STEAM

This work is the research results of the following projects.

-The"13th Five-Year Plan"education science project in ShanXi Province in2016:Cultivation of STEM skills of science teachers--Taking experimental lessons as an example(GH-16075);

-ShanXi Province Education Science"13th Five-Year Plan" Basic education promotion plan special topic:Research on Teaching Innovation Capacity Development in middle school physics teachers (ZJ-17028);

- Teaching Reform Project in 2019 of Taiyuan Normal University:Practical Research on Case in Physics Teaching Theory Courses(JGLX1955) and Exploit Case Research on the High School Physics Teaching based Core Literacy(JGZX1902);

-Establish-morality-Cultivate-HumanBasicEducation Service Action Plan Project:Research on Experimental Teaching Strategy of Developing Physics Core Literacy in Secondary Schools. concepts in physics education can enable students to solve practical problems in production and in living through interdisciplinary knowledge and skills, to carry out scientific exploration, to correspond the technical learning, and to have the ability to design and think in engineering. This will contribute to the development of students' science (physics) literacy and core literacy.

\section{A. Overview of STEAM education}

Scholars coming from different countries have different views on the STEAM education concepts' interpretation. Some people explained it from the perspective of creation and integration, thinking that STEAM education is integrated science education, is similar to higher science education in China. However, others described it from a student-centered perspective, so that it is considered to be a kind of science education that is really student-centered teaching. In the past ten years, STEAM education has been considered as a well interdisciplinary teaching method. It is an educational methodology that combines with science, technology, engineering, art and mathematics, so that students are able to achieve organic integration form STEAM learning. Students mainly rely on basic mathematical knowledge to design engineering projects and solve the actual questions, and learn the connotation of science and technology which they draw lessons form STEAM skills and STEAM knowledge. So far, STEAM education has been widely used in science education to improve teachers' teaching, students' learning strategies, students' practical application capabilitiesetc ${ }^{[2]}$.

\section{B. Overview of the " $6 E$ "design learning process}

The American Science Curriculum Promotion Research Association(SCIS) proposed a basic teaching model for STEM education in 1960, it was included three steps:exploration, invention and discovery ${ }^{[3]}$.In 2006, Professor Barry ${ }^{[4]}$ from the United States proposed the " $5 E$ " teaching process of STEM education, the " $5 \mathrm{E}$ " teaching process was engage, explore, explain, engineer and evaluate. In 2014, the International Association of Technical and Engineering Educators(ITEEA) proposed a student-centered " $6 \mathrm{E}$ " teaching and learning process which was based on " $5 \mathrm{E} "$ "[5] .The " $6 \mathrm{E}$ " design learning process guides students through interdisciplinary comprehensive learning, they are"engage, explore, explain, engineer, extend and evaluate", it can gradually deepen STEAM education through the practice process and the output products.Chih-ChaoChung ${ }^{[6]}$ studied on "STEAM-6E Learning 
on Creative Design of Internet of Things for the Elderly" in Taipei, China, which strengthened students'ability to integrate STEAM knowledge and improved their learning efficiency in various disciplines.N. Khaeroningtyas ${ }^{[7]}$ and others investigated on 'the ' $6 \mathrm{E}$ ' Learning Method Using Engineering and Technology Design in Indonesia”.Their STEM learning was based on research with the high-temperature materials and changes, and the STEAM process which based on the $6 \mathrm{E}$ learning process has improved the students' scientific literacy in junior high school.

The concrete 6E design learning process is as follows:(1)Engage:Teachers identify the appropriate STEAM curriculum content, stimulate students'curiosity, interest and participation, and define the STEAM theme and the goal of the activity. (2)Explore: Students establish their own learning. Teachers use STEAM knowledge in various fields to design simple solutions for students to thinking, encourage students to use the knowledge they have learned, to solve problems, and learn to accumulate experiences. Teachers ask students to form a group discussion, exchange opinions with each other, and deepen understand their basic knowledge. (3)Explain: Students explain and improve the science knowledge that they have learned. At this stage, teachers need to conduct the systematic structured cognitive guidance for students. Teachers should also point out the mistakes which made by students and provide guidance for them. At the same time, the teacher leads the students to discuss or clarify the uncertain concepts and solve problems through questions and answers.(4)Engineer: Students apply their solutions, materials, and tools to practice. Students must integrate the knowledge and skills which they have learned and carry out the engineering design and produce the products to solve their problems in this STEAM education stage. (5)Extend: In order to explore the more deeply and apply STEAM questions and make STEAM education more widely, students are required to solve problems in different dimensions and solve more complex problems in this stage. (6)Evaluate: Teachers and students make judgments and analyse their learning results. Teachers set the test standards and use the test tools to measure students' learning outcomes and deficiencies. Each process of the 6E design learning process mode the represents of a complete system. Since students must continue to think in every process, so these learning programs are suitable for students' STEAM learning and teachers' STEAM teaching.

\section{METHODS}

This study used two teaching research methods. Method one is case study. Based on the analysis of the Physics Textbook and the discussion of the teaching objectives proposed in the Physics Curriculum Standard(2011), and in combination with the requirements and characteristics of STEAM education, a case of noise reduce device in grade two in junior high school is selected for teaching design. Rational and speculative thinking were used in the design of STEAM teaching. The case teaching based on the STEAM concepts was specific $6 \mathrm{E}$ design learning process. The second method is experimental research so as to explore how is the effects of actual implementation of the designed STEAM teaching cases.

\section{A. Case study: Teaching of noise reduce device}

\section{1) Preliminary analysis of physics and STEAM}

With the rapid development of social economic level and urbanization, both private and public transportation have gradually increased, hence, all kinds of hazard noises become more and more in our dairy life. In order to achieve the harmonious coexistence from humans with the cities' environment, human reduce the noise pollution with reasonable way has become a practical significance topic. People can restrict the movement of various types of vehicles, and they can also reduce noise by changing traffic flow. However, it is more important to find the ways to set up noise reduction devices for various types of vehicles which such as automobiles, light rails, and subways, it can reduce noises from the sound sources, and should do a good job in the urban environmental optimization works.So this STEAM design is based on the scientific knowledge of the"Hazard and Control of Harmful Noise”. It involves knowledge such as material science, sound transmission and its calculation, and introduces the noise engineering problems that need to be solved in urban living. In the process of hands-on practice, students can cleverly experience the organic integration of science, technology, art, engineering, and mathematics.They also can create noise reduction devices, and experience the " $6 \mathrm{E}$ " process which is "engagement, exploration, explanation, engineering, extending and evaluation”and they can cultivate their scientific literacy. Let the students consolidate the learned knowledge in the process of analyzing and solving the problems, and it can guide the students to learn to find the breakthrough and the ideas for solving new problems when they studied or worked.

\section{2) Analysis of students}

The eighth grade students(14-15 years-old)already have a certain understanding of the production and transmission of sounds, and of the characteristics of sounds, and the hazards and control of noises. The thinking of the students is active, their desire for knowledge is strong, and students are full of curiosity about many phenomena in nature.With the strong hands-on ability, students can complete the noise reduction device design and production.

3) Design teaching objectives from STEAM curriculum to physics curriculum

In sound phenomenon field in the junior high school, "noise" is a core concept(the basic concept of the discipline).The analysis of the core concept of noise involves the definition, generation, harm, and controls.The specific presentation and analysis can be shown in the content of the Curriculum Standards.The STEAM teaching objectives and its analysis of the design and production of the noise reduction devices can be seen in table I. 
TABLE I.

STEAM EDUCATION TEACHING OBJECTIVES AND PHYSICS CURRICULUM STANDARDS DEMAND WITH HAZARD NOISE

\begin{tabular}{|c|c|c|c|}
\hline & STEAM education teaching target(SETT) & $\begin{array}{l}\text { Physics Curriculum } \\
\text { Standards demand(PCSD) }\end{array}$ & $\begin{array}{l}\text { The connection between } \\
\text { SETT and PCSD }\end{array}$ \\
\hline Science & $\begin{array}{l}\text { 1.Know the knowledge of the harm of noise and its preventing principle } \\
\text { and methods; } 2 \text {.Know the common sound medium propagation } \\
\text { characteristics, and sound material absorption characteristics; 3.Calculate } \\
\text { sound speed and understand the decibel units. }\end{array}$ & \multirow{5}{*}{$\begin{array}{l}\text { 1.The noise which is associated } \\
\text { with the production of living is } \\
\text { understood with its generation } \\
\text { and its harm performance; } \\
\text { 2.Know the knowledge of } \\
\text { hazard noise and the methods of } \\
\text { controlling its; } \\
\text { 3.Design and investigate the } \\
\text { environmental } \\
\text { noise reduction } \\
\text { Methods. }\end{array}$} & $\begin{array}{l}\text { STEAM education target } \\
\text { reflects the knowledge and skill } \\
\text { goals in the Physics } \\
\text { Curriculum Standards. }\end{array}$ \\
\hline Technology & $\begin{array}{l}\text { 1.Learn how to design noise reduction devices; 2.Identify the technology } \\
\text { about sound absorption effects of different substances; 3.Application the } \\
\text { technology of decibel meter; 4.Learn the computer technology, etc. }\end{array}$ & & $\begin{array}{l}\text { SETT reflects the basic } \\
\text { concepts, process and method } \\
\text { goals in the PCSD. }\end{array}$ \\
\hline Engineering & Design and manufacture the noise reduction devices. & & $\begin{array}{l}\text { SETT reflects the cultivation of } \\
\text { scientific literacy in the PCSD. }\end{array}$ \\
\hline Art & $\begin{array}{l}\text { 1.Describe the principle and appearance of the existing noise reduction } \\
\text { device; 2.Design the drawings and describe its artistic features;3.The } \\
\text { design of the noise device is beautiful and suitable. }\end{array}$ & & $\begin{array}{l}\text { SETT reflects the } \\
\text { embody emotional attitudes } \\
\text { and values in the PCSD. }\end{array}$ \\
\hline Mathematics & $\begin{array}{l}\text { 1.The amount of used materials will be calculated flexibly according to the } \\
\text { actual needs and budgets; } 2 \text {.Calculate the decibels, sound velocities, etc. }\end{array}$ & & $\begin{array}{l}\text { SETT reflects the penetration } \\
\text { of the discipline ideas in the } \\
\text { PCSD. }\end{array}$ \\
\hline
\end{tabular}

The Table I are the teaching objectives and requirements of STEAM education in science, technology, engineering, art and mathematics, and in the middle are the teaching requirements of the section on noise hazards and prevention in Physics Curriculum Standards, and on the right are the link between STEAM education objectives and the requirements of Physics Curriculum Standards in this section. As we can see from Table I, the objectives of STEAM education and the description of Physics Curriculum Standards have some similarities and differences in their basic practices and concepts. The analysis of Physics Curriculum Standards in the basic education can be translated into the teaching goals of STEAM education.

\section{B. Experiment design}

\section{1) Experimenter}

The student number of 1703 (class name) is 56, including 27 boys and 29 girls in No.2 middle school in Jin Zhong city, Shan Xi province, China. The student number of 1706 is also 56, including 29 boys and 27 girls. The proportion of men and women in each class is also the same.According to the self-compiled questionnaire survey on the level of STEAM education understanding among these students, the $\mathrm{F}$ test of the pro-test difference of the two class was carried out. The test results are shown in Table $\mathbb{I}$. The results show that the STEAM understand difference $\mathrm{F}$ value between students of two class is $1.913(\mathrm{P}>0.05$ Sig. $=0.061 \mathrm{~F}=1.67 \mathrm{df}=60)$. The results is showed that there was no significant difference in the understanding of STEAM education between the two classes, and the subjects were homogeneous.

TABLE II. CHARACTERISTICS AND DIFFERENT OF STUDENTS

\begin{tabular}{|l|c|c|c|c|c|c|c|c|c|}
\hline & Class No. & Number & Boys & Girls & average value & Standard deviation & Standard Error ofMean & F & Sig. \\
\hline \multirow{2}{*}{$\begin{array}{l}\text { Protest } \\
\text { results }\end{array}$} & Experiment class & 56 & 27 & 29 & 112.7407 & 7.95464 & 1.53087 & -1.913 & .061 \\
\cline { 2 - 9 } & Control class & 56 & 29 & 27 & 112.0385 & 8.39753 & 1.64689 & -1.911 & .061 \\
\hline
\end{tabular}

2) Questionnaire

The above survey of junior high school students' understanding of STEAM education consists of 29 multiple-choice questions. The first question is the understanding of students' basic physics performance. STEAM education is a kind of comprehensive inquiry education. STEAM literacy contains not only knowledge and ability, but also various factors such as methods, thinking, ideas, and emotions ${ }^{[8]}$.So The remaining 28 questions mainly examine students' understanding of STEAM education from six dimensions: knowledge, concept, thinking, ability, method, and emotion. The number of questions in each dimension is distributed between 4-6. The distribution of topics under each dimension is shown in table III. These topics are based on the "STEM Literacy Questionnaire" in "Design and Practice of Secondary Chemistry Teaching Based on STEM Education Ideas: An Example of Making a Mirror", ${ }^{9]}$, and at the same time is made many modifications.

In this study, the consistency of student questionnaire scores was measured by half-confidence and re-confidence measurement, and SPSS19.00 was used to make statistical analysis of the two test data. From the statistical results, it can be seen that the reliability coefficient is 0.744 and the correlation coefficient Cronbach's $\alpha$ is 0.812 , it show that the reliability of the questionnaire is good.

Factor analysis was used to measure the validity of the questionnaire. The KMO test and the Bartley sphere test were performed first to see if the data could be analyzed by factors. This KMO value is 0.739 ,shows that the questionnaire has a good structural validity. Since the KMO value is 0.5-0.9, indicating that the questionnaire validity is acceptable.As shown in table $\mathrm{IV}$, the correlation coefficients of each dimension are between 0.712 and 0.856 ,so the validity of the questionnaire is very good.

\section{3) Experiment process}

The students of 1706 and 1703 were taught by the same physics teacher. The students of the experimental class(1703) did not tell the purpose of the experiment and the specific purpose of the process. The students of control class(1706) also did the pretest and post-test questionnaires. 
TABLE III. DIMENSIONS AND TITLE NUMBERS OF QUESTIONNAIRES

\begin{tabular}{|c|c|c|}
\hline $\begin{array}{c}\text { First } \\
\text { dimension }\end{array}$ & Secondary dimension & $\begin{array}{c}\text { Title } \\
\text { number }\end{array}$ \\
\hline Knowledge & Physics knowledge, STEAM knowledge & $2,3,4,17$ \\
\hline \multirow{2}{*}{ Method } & $\begin{array}{c}\text { Physics Methods, Mathematical Methods, } \\
\text { Design and Engineering Methods }\end{array}$ & $\begin{array}{c}6,13,26, \\
27\end{array}$ \\
\hline \multirow{2}{*}{ Emotion } & $\begin{array}{c}\text { Scientific Emotion, Social Responsibility } \\
\text { and Attitudes, Motivation }\end{array}$ & $\begin{array}{c}5,11,14, \\
15,16\end{array}$ \\
\hline Concept & $\begin{array}{c}\text { Material concept, Energy, Movement, } \\
\text { STEAM }\end{array}$ & $\begin{array}{c}7,8,9,10, \\
12\end{array}$ \\
\hline \multirow{2}{*}{ Thought } & $\begin{array}{c}\text { Physics thinking, scientific observation, } \\
\text { mathematical thinking }\end{array}$ & $\begin{array}{c}18,19,20, \\
25,28,29\end{array}$ \\
\hline \multirow{2}{*}{ Ability } & $\begin{array}{c}\text { STEAM ability, observation ability, } \\
\text { innovation ability }\end{array}$ & $\begin{array}{c}21,22,23, \\
24\end{array}$ \\
\hline
\end{tabular}

The questionnaire is used for the pretest and post-test of classroom teaching experiments. Among them, the purpose of the pretest is to understand the subjects and thus judge the STEAM literacy they have, thus providing guidance for the design and implementation of STEAM teaching cases. After conducting classroom teaching experiments, this questionnaire was used again to make post-test.The purpose was to test the experimental process effects of STEAM cases, whether the level of understanding of STEAM education by different students has changed, and whether the student's STEAM literacy has been improved.

TABLE IV. STRUCTURAL VALIDITY OF QUESTIONNAIRES

\begin{tabular}{|c|c|c|c|c|c|c|}
\hline $\begin{array}{c}\text { Dimensions } \\
\text { Correlation }\end{array}$ & Knowledge & Method & Emotion & Concept & Thought & Ability \\
\hline Knowledge & & 0.744 & 0.814 & 0.875 & 0.734 & 0.712 \\
\hline Method & 0.744 & & 0.767 & 0.738 & 0.856 & 0.801 \\
\hline Emotion & 0.814 & 0.767 & & 0.785 & 0.836 & 0.764 \\
\hline Concept & 0.875 & 0.738 & 0.785 & & 0.789 & 0.764 \\
\hline Thought & 0.734 & 0.856 & 0.836 & 0.789 & & 0.748 \\
\hline Ability & 0.712 & 0.801 & 0.764 & 0.764 & 0.748 & \\
\hline
\end{tabular}

Students in the experiment class studied STEAM for three months when they were required to study normally. During the course of teaching, another two-three teachers observed the students on the spot and gave them the self-evaluation form and the group evaluation form. The teacher needed to collect and organize information in advance, and prepared the equipment.Students needed to collect relevant information, investigated related issues, and used the topic to produce related works. The experiment process was carried out in strict accordance with the requirements of teaching experiments and the irrelevant variables were controlled.The control class students conducted teaching according to the school's daily teaching and the teaching progress remained consistent.

There are something to been known:(1)Experimental purpose: After the testing of the teaching experiments of cases, whether the students' understanding of STEAM education will been improved. (2)The experimental hypothesis: After the teaching experiment, the experimental subjects' post-test results will be better than the pretest results, forming a contrast, and there will be no significant changes in the control class students.(3)Experimental variables:The independent variable was the implementation of teaching design cases of "Design and Application of Noise Reduction Devices"; The dependent variable was the student's understanding of STEAM education reflected in the student's questionnaire test results or the student's STEAM literacy; The control variables are experimental environment, teachers, experimental instruments, assessment standards, parents, student' professional background, existing knowledge, learning ability, and teaching environment.

\section{Results}

\section{A. Design of teaching Process}

The STEAM education activity based on the $6 \mathrm{E}$ design learning process was flowed.The activity was "noise reduction device design and production”and the teaching process design case can be seen in the table $\mathrm{V}$.

TABLE V. “NOISE REDUCTION DEVICE DESIGN AND PRODUCTION” ACTIVITY PROCESS

\begin{tabular}{|c|c|c|c|c|}
\hline \multirow{2}{*}{\multicolumn{2}{|c|}{$\begin{array}{c}\text { Theme of the event } \\
\text { Scenario issues }\end{array}$}} & \multicolumn{3}{|c|}{ Design and Product the Noise Reduction Devices } \\
\hline & & \multicolumn{3}{|c|}{ How to prevent and reduce the harmful noise in living? } \\
\hline \multicolumn{5}{|c|}{ Activities process arrangements } \\
\hline $\begin{array}{l}\text { Teaching } \\
\text { procedure }\end{array}$ & Teaching link & Teacher's activities & Background information & Student's activities \\
\hline Engagement & $\begin{array}{l}\text { Design the } \\
\text { teaching } \\
\text { situations; } \\
\text { Raises the } \\
\text { questions for } \\
\text { teaching. }\end{array}$ & $\begin{array}{l}\text { (1) Introduce the "quietest place in the } \\
\text { world” --the sound absorption laboratories } \\
\text { in United States (Orfield Laboratories), } \\
\text { lead to teach the theme of "noise } \\
\text { reduction.” } \\
\text { (2) Ask questions to Students: Which } \\
\text { devices in daily life are equipped with } \\
\text { noise reduction or muffler devices? how } \\
\text { these devices work?And what are their core } \\
\text { components? } \\
\text { (3) Divide the students into many groups } \\
\text { and lead the students' group to discuss and } \\
\text { try to design a muffler. } \\
\text { (4) Review the scientific knowledge of } \\
\text { noise. }\end{array}$ & $\begin{array}{l}\text { (1)The } 99.99 \% \text { of the voices in the Orfield } \\
\text { Laboratory are absorbed, making it the quietest } \\
\text { place on the planet identified by Guinness World } \\
\text { Records. This effect is achieved by the use of } \\
3.3 \text { feet( } 1.01 \text { meters) thick glass fiber sucking } \\
\text { spikes, double-insulated steel walls, and } 1 \\
\text { foot( } 30.48 \mathrm{~cm} \text { ) thick concrete. People can } \\
\text { clearly hear their own heartbeat, breathing and } \\
\text { other little sounds inside. } \\
\text { (2)The common noise reduction devices are } \\
\text { centrifugal wind noise reduction, noise } \\
\text { reduction for transformers, road traffic noise } \\
\text { reduction, bridge waveform noise reduction, } \\
\text { chemical noise reduction, landing gear noise } \\
\text { reduction and so on. }\end{array}$ & $\begin{array}{l}\text { (1)Watch video, } \\
\text { understand the content of } \\
\text { the video situation, and } \\
\text { clarify the event theme. } \\
\text { (2) According to their } \\
\text { own understanding, } \\
\text { collect relevant } \\
\text { information and discuss } \\
\text { the questions by groups in } \\
\text { the Internet. } \\
\text { (3)Based on issues, } \\
\text { design preliminary } \\
\text { framework of noise } \\
\text { reduction devices and } \\
\text { make a decision of labor } \\
\text { division. }\end{array}$ \\
\hline
\end{tabular}


(1) Guide students to analyze data and use brainstorming methods to reason solutions about the key noise reduction problems. (2)Guide students to design, discuss, Teacher show the task requirements and precautions.Students were assigned their tasks. (Materials were provided are timers, felt, newspapers, cotton, tape,Cardboard boxes, Decibel meters, scales, wet meters, thermometers.)

(3)Carry out the observation and design the guidance of each group.

Discuss and explore;

Exploration Formulate a plan.
(1) Make students to know the level of noise, to clarify the noise hazards in life, and understand the principle of noise reduction devices, and analyze the acoustic characteristics of the preventing noise materials provided.

(2)Guide students to share their own designs and plans. Teachers analyze scientific nature and the feasibility of their designs and summarize them.

analyze and think in this

Explanation process; explain their plans.

(3)Introduce the commonly used noise ideas do you have for design? Make reduction device design technology. What students to know how to answer those questions. Such as, was the acoustic absorption effect of the noise reduction device which you designed produced by one layer of material or by multiple layers of material? Does your design consider the airtight bodies? What are the characteristics of Wall materials and shapes in American sound-absorbing laboratories? What's the message to you?

(1)Organize students' groups to make the noise reduction devices. It is emphasized that the operation steps of the production process should be reasonable and must pay attention to safety.

Operate the instruments and implement the noise reduced device production.
(2)Assist students in solving problems in the production process and conduct guidance and evaluations in the student's operation process.

(3)Conduct process evaluation based on the characteristics of STEAM and propose further improvement suggestions, such as how to make the secondary noise reduction devices and so on.
(1)Noise reduction design principle are include sound barrier noise, plant noise reduction, isolation near sound source, reducing reverberation, improving the sound insulation of materials, human ear belt sound

insulation equipment.

(2)We should introduce the Folium Meters and analysis the multilayer and porous materials.

(3)Thickness, capacity or voids, flow resistance, temperature and humidity are the main factors

that affect the sound absorption effect.

(4)The sound absorption coefficient and the sound absorption coefficient of the material are related to its sound frequency.

(5)The ratio of the sound energy absorbed and transmitted by the material to the total sound energy incident on the material is called the sound absorption coefficient.

(6)Different materials have different quality of sound absorption. According to ISO standards and national standards, the frequency range of sound absorption factors in the sound absorption test report is $100 \mathrm{KHz}-5 \mathrm{KHz}$.

(7)The average sound absorption coefficient of $100 \mathrm{KHz}-5 \mathrm{KHz}$ is the average sound absorption coefficient, and the average sound absorption coefficient reflects the overall sound absorption performance of the material.

(8)The Voice absorption coefficient of felt: $0.26-0.42$; the sound absorption coefficient of Newspaper: 0.19-2.28; the sound absorption coefficient of Cotton: 0.74-0.88.

(1)The Design technology is included the sound insulation technology, sound absorption technology and vibration isolation technology. The sound insulation technology is the management of sound isolation based on sound insulation structures and materials. The sound absorption technology is the process of selecting sound absorption structures and materials. The vibration isolation technology is using the damping and elastic components to connect vibration sources and to achieve the effect of reducing isolation vibration. (2)The design ideas are actively control methods(isolation sound source)and passive control methods(isolation object)which were using when we select material and optimize structures.

(3)The design drawings are the design of materials, dosage, size, specifications, etc.. (4)We ask the students to make the charts and the performance of the design devices to be beautiful.

(1)The acoustic characteristics of the three materials are compared as follows: cotton is the strongest, felt is second, and newspaper is the weakest.

(2)The control variables are the same as the control thickness, temperature, humidity, capacity, and flow resistance.

(3)The best design is to accommodate generators, cotton about $250 \mathrm{~g}$, porous layered thin layer design, humidity about $19 \%$ (need to be dry), conducted at room temperature.

(4)Teacher design activity record sheet, evaluation form, experimental data sheet, etc. are presented to students.
(1) Analyze the principle of noise reduction through pre-class prepared and in-class seeking materials and teacher's explanations, involving their understanding of noise knowledge.

(2) Discuss, design, and draw up the design plans actively in during the group activities.

(1)Clarify the connotation of each knowledge and complete the construction of each knowledge of hazard noises and noise reduction devices.

(2)Express, listen, evaluate their design plans, and clarify the methods and requirements for designing the noise reduction devices technology.

(3)Master the corresponding scientific knowledge and design technology.

(4)Have the certain technical design ideas.

(1)According to the design ideas and plans in the group, carry out experimental design and operate them, and make the finished products.

(2)Check the noise reduction device their designed and fill data in the forms which teacher gives.

(3)Analyze and optimize the noise reduction device continuing and formulate the content expressed when those displaying works. 
(1)Industrial noise reduction optimization schemes are a combination of schemes that take into account the spectrum characteristics and the location of sound sources, produce requirements, and outstanding performance in cutting-edge technology especially.

(2)The Grade A noise level achieved by noise reduction can be about 3 to 8 decibels $(\mathrm{dB})$ in the general workshops; the noise reduction of the building with a special geometry(acoustic focus) and a severe reverberation are about 12 decibels.

(1)Guide students to conduct inter-group's exchanges, to show the production progress for other groups, to find problems, and students' questions and evaluate each other. (2)Summarize the students' problems and select the best programs, suitable materials and the best students. The teacher motivate everyone to continue their efforts and emphasize the importance of the process. (3)Lead students to propose further solutions and ideas, and continue to innovate.

(3)When the area of the workshop is large, especially the flat workshop, it is treated generally only by the flat top sound absorption treatments. When the sound sources are concentrated in the local area of the workshop, local sound absorption treatments should be performed on the ceiling and walls of the area where the sound sources are located, and a sound barrier should be set up where the sound sources are located.

(4)The optimization methods for living noise reduction are generally four methods:1)If the room area is small, the ceiling and wall should be sound-absorbing at the same time.(2)The sound absorption effect is not proportional to the sound absorption treatment area, and the space sound absorption area should take about $40 \%$ of the flat top area of the room or about $15 \%$ of the total indoor surface area.(3)The height of the suspension of the spatial sound absorber should be lower and closer to the sound source.(4) Sound absorption noise reduction design at the same time to meet the requirements of fire, moisture, dust, ventilation, lighting and so on.

(1)There are seven art evaluation standards: beautiful, science, decent, reasonable, high technology, a number of technologies, excellent reporting.

(1)Organize students to perform group presentations and report on the production process to record the students' highlights and mistakes.

The showing (2)Summarize students' experience and

work and the enhancement feelings of activities and guide students to experience the knowledge, skills,

computing, technology, engineering, art, society, and the awareness of environmental protection involved in STEAM activities.

(3)Summarize STEAM activities.
(2)The representation of evaluation criteria for noise reduction devices include the following aspects:language expression is smooth, students use the scientific knowledge to expressed, the obviously technical characteristics of the devices are presented, problems are analyzed from multiple angles, and the devices express the life reality and the industrial production are combined.

(3)The noise reduction devices are used more in industry, especially in high technology, such as computer hardware design and watch design. It is also widely used in cutting-edge technology, such as aerospace engineering design.
(1)Report for all class by representatives of each group.

(2)Listen, question and evaluate the design and the presentation of the results of every group.

(3)Discuss with your own group to optimize and discuss the plan.

\section{B. Experimental results}

\section{1) Actual teaching process}

There are three pictures here, the Fig. 1 is students were working in their classroom;the Fig. 2 is a internal of the controlling noise device;the Fig. 3 is a external of the controlling noise device.

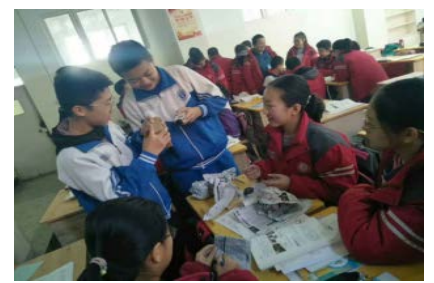

Fig.1. Students were working in the classroom by group.

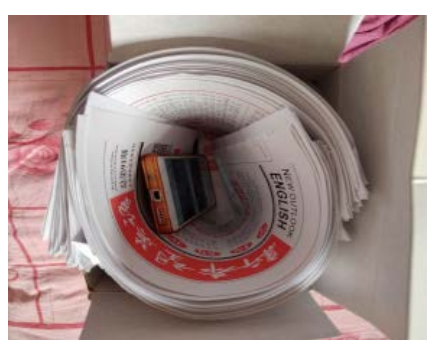

Fig.2. The internal of the controlling noise device, the mobile telephone is the noise source ,the newspaper is the sound-proof material, they are in the box.
(1)Improve the content of the group's report and summarize the activities. (2)Complete the final finishing works, sum up STEAM activities with teachers, sublimate knowledge, and expand social applications and the high technology. 


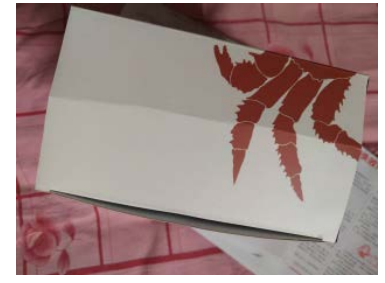

Fig.3. The external of the controlling device, students' box is the same in size, material, thickness, etc.

\section{2) Results of pretest data}

The data collected were processed after the pretest of the questionnaire and were aggregated according to the six dimensions of knowledge, methodology, emotion, perception, thinking and ability, as shown in table VI. Among them, the statistical results of the data in the table are calculated as a percentage. For example, the “15.3\%" of the knowledge dimension of the experimental class was calculated as follows: First, the options in the topics under each dimension in the questionnaire are assigned, the " $\mathrm{A}$ " option is assigned 3 points, the " $B$ " option is assigned 2 points, and the " $C$ " option is assigned 1 point.There are 4 topics in the dimension of knowledge, so the full score of this dimension is 12 points; Finally, using the Excel statistics, the average score of the experimental class students on this dimension was obtained. Divided by 12 by this average and multiplied by $100 \%$, “15.3\%"can be obtained.

TABLE VI. SUMMARY OF PRETEST TESTS FOR TWO CLASSES

\begin{tabular}{|c|c|c|c|c|c|c|}
\hline & Knowledge & Method & Emotion & Concept & Thought & Ability \\
\hline Experiment class & $15.3 \%$ & $18.2 \%$ & $15.1 \%$ & $12.9 \%$ & $10.2 \%$ & $10.9 \%$ \\
\hline Control class & $18.4 \%$ & $17.1 \%$ & $16.4 \%$ & $15.3 \%$ & $15.3 \%$ & $16.2 \%$ \\
\hline
\end{tabular}

TABLE VII. F TEST OF GROUP DIFFERENCE OF EXPERIMENT CLASS AND CONTRIOL CLASS

\begin{tabular}{|c|c|c|c|c|c|}
\hline & f & df & Sig.(Bothsides.) & Mean difference & Standard Error of Mean \\
\hline Assuming variance is equal & -1.837 & 112 & .073 & -4.56782 & 2.23517 \\
\hline $\begin{array}{c}\text { Suppose the variance is not } \\
\text { equal }\end{array}$ & -1.918 & 111.567 & .068 & -4.29872 & 2.24731 \\
\hline
\end{tabular}

As we can see from table VI, more than $10 \%$ of students in both classes had a certain understanding and understanding of STEAM education in the six dimensions, especially in the three dimensions of thinking, methods, and abilities. More than $10 \%$ of students perform was well.However, it had not reached a high level of understanding of STEAM education, which will help the development of classroom teaching practice activities. As shown in table VII, the total score of STEAM literacy of second time by $\mathrm{F}$, and there was no significant difference from the level of significance. It shows that the two groups of students had the similar characteristics and had a little understanding of STEAM education concepts. Interviews with students also revealed that 80 percent had not heard of STEAM education, while only 10 percent had heard of it.

\section{3) Post-test data results}

TABLE VIII. SUMMARY OF POST-TEXT DATA FOR TWO CLASSES

\begin{tabular}{|c|c|c|c|c|c|}
\hline & Knowledge & Method & Emotion & Concept & Thought \\
\hline Experiment Class & $69.3 \%$ & $76.2 \%$ & $65.1 \%$ & $64.9 \%$ & $76.2 \%$ \\
\hline Control Class & $19.3 \%$ & $16.6 \%$ & $16.7 \%$ & $66.5 \%$ & $15.8 \%$ \\
\hline
\end{tabular}

Due to the longer interval, the student's exercise effect was lower, and the collected data was then processed, and the results are shown in table VIII. It can be seen that the STEAM knowledge and methods of experiment students had improved in six aspects, ranging from $50 \%$ to $60 \%$. The six aspects of the control class students had barely changed, indicating that the teaching based on the STEAM concepts had been effective.

From the variance test of the significant differences between the total score of two classes in table $\mathbb{X}$ and the dimensions of them in table $\mathrm{X}$, it is shown that the STEAM awareness of the experiment class was significantly higher than that of the control class, with significant differences, especially in STEAM emotions, concepts, and knowledge.

TABLE IX. SINGLE FCTOR VARIANCE ANALYSIS OF EXPERIMENT CLASS AND CONTROL CLASS IN POST-TEST DATA

\begin{tabular}{|c|c|c|c|c|c|}
\hline & Sun of Squares & df & Mean Square & F & Sig. \\
\hline Between Groups & 4.882 & 3 & 1.591 & 3.327 & $.010^{*} *$ \\
\hline Within Groups & 333.312 & 112 & .478 & & \\
\hline Total & 338.194 & 115 & \multicolumn{5}{|c|}{${ }^{*}$ Indicates $\mathrm{P}<0.05$; ** indicates }
\end{tabular}

TABLE X. MULTIPLE COMPARISON RESULTS OF POST-TEST DATA OF EXPERIMENT CLASS AND CONTROL CLASS

\begin{tabular}{|c|c|c|c|c|c|c|c|}
\hline & Experiment Class & Control Class & Sig. & & Experiment Class & Control Class & Sig. \\
\hline \multirow{11}{*}{ LSD } & Knowledg-e & Knowledge & $.000 * * *$ & \multirow{11}{*}{ LSD } & Emotion & Emotion & $.000 * * *$ \\
\hline & & Method & .110 & & & Concept & .147 \\
\hline & & Emotion & .356 & & & Thought & .048 \\
\hline & & Concept & .218 & & & Ability & .156 \\
\hline & & Thought & .156 & & Concept & Concept & $.000 * * *$ \\
\hline & & Ability & .258 & & & Thought & $.034 *$ \\
\hline & Method & Method & $.018 * *$ & & & Ability & .089 \\
\hline & & Emotion & .347 & & Thought & Thought & $.047 *$ \\
\hline & & Concept & .273 & & & Ability & .065 \\
\hline & & Thought & .152 & & Ability & Ability & $.034 *$ \\
\hline & & Ability & .114 & & & & \\
\hline
\end{tabular}




\section{4) Results of comparison of Pretest and post-test data}

The results of the pretest in table VI were compared with the results of the post-test in table VIII and were made into a convoluted statistical graph, as shown in the data of the experiment class in Fig 4 below and the data of the control class. From the figure, it can be seen intuitively that whether it is the difference between experiment class or control class in the teaching process, there is a certain increase in the value compared to the previous test.Especially in the three dimensions of knowledge, emotion, and concept, the increase was more obvious, indicating that after the STEAM classroom teaching practice activities, students not only learned relevant physics knowledge and scientific skills in the process of hands-on design and production of devices, but also had a certain understanding of STEAM education. In addition, from the perspective of the six dimensions of the method, thinking, and ability etc., it was only slightly rising. The reason is mainly caused by the short teaching experiment.The acquisition of methods, the transformation of thinking styles, and the improvement of abilities all require long training to be achieved.From the overall point of view, classroom practice was still relatively successful, indicating that the design of junior high school physics teaching under the STEAM education concept had a certain role in promoting students' knowledge, ideas, and emotions, and helped students to understand STEAM education. The STEAM literacy of students had been effectively improved.
As shown in Table $\mathrm{XI}$, the variance analysis of the front and back measurement data of the experimental class shows that the front and back measurement data of the experimental class had significant differences in the six aspects of STEAM, while the front and rear measurement data of the control class had no significant changes in the six aspects of STEAM.The variance was homogeneous, but the analysis results were not significant, so the data was not presented. This is consistent with the post-test data test above.

\section{DISCUSSTION}

This STEAM curriculum is designed to allow students to learnthe devices in daily life which have noise reduction or muffler, to makethe devices and to understandtheworking principles of these devices and the structure of core components.

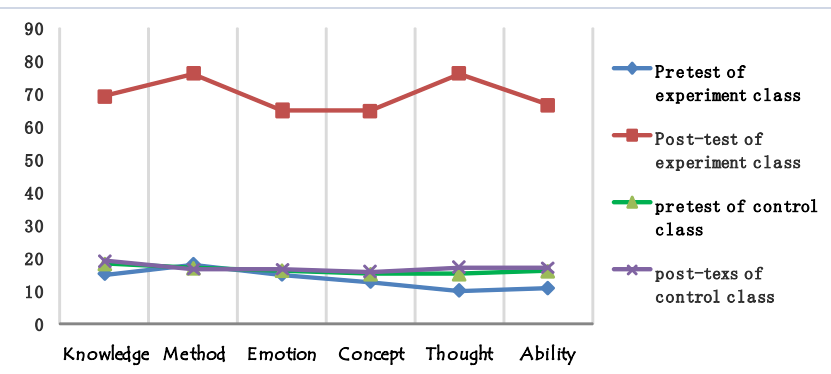

Fig.4. Diagram of six dimensions of experiment class, control class before and after the measurement

TABLE XI. ANALYSIS OF VARIANCE OF THE PRETEST AND POST-TEST DATA OF EXPERIMENT CLASS

\begin{tabular}{|c|c|c|c|c|}
\hline Content & Pretest(M \pm SD) & Post-test(M \pm SD) & $\mathbf{F}$ & Sig. \\
\hline Knowledge & $1.836 \pm 4.725$ & $8.316 \pm 3.706$ & 3.452 & $.000^{* * *}$ \\
\hline Method & $2.184 \pm 14.727$ & $9.144 \pm 6.358$ & 9.214 & $.008 * *$ \\
\hline Emotion & $2.265 \pm 7.244$ & $9.765 \pm 10.371$ & 5.060 & $.000^{* * *}$ \\
\hline Concept & $1.935 \pm 6.667$ & $9.735 \pm 6.357$ & 4.891 & $.000 * * *$ \\
\hline Thought & $1.836 \pm 6.435$ & $13.716 \pm 7.562$ & 3.452 & $.002^{* *}$ \\
\hline Ability & $1.308 \pm 10.473$ & $7.228 \pm 12.813$ & 2.211 & $.005^{* *}$ \\
\hline $\begin{array}{l}\text { STEM literacy } \\
\text { (Total score) }\end{array}$ & $11.388 \pm 27.446$ & $58.924 \pm 41.952$ & 7.267 & $.000 * * *$ \\
\hline
\end{tabular}

\section{A. Analysis of instructional design}

In the classroom, the teaching design reflects the $6 \mathrm{E}$ design learning process. First, it was leaded students to review the knowledge about the generation and transmission of sounds, the hazards of noise, the prevention of noise and the control of noise. It recognizes some common sound absorption devices and materials, creating a situation, allowing students to participate in activity learning, raising questionsrelated to life, and improving their interest. second, the subject of inquiry is introduced to allow students to design noise reduction devices through group cooperation. Third, the teacher and the students explain and optimize the design schemes.Fourth, students carry out the implementation of the project, the production of noise reduction devices and the testing of the sound absorption, it make their own ideas into reality. fifth, students of each group carry on the exchange design and the reflection, discovering the new problem that can carry on the solution, consummating the best design plan. Sixth, the results of the noise reduction device production are presented, reported and evaluated. Teachers guide and inspire students to know how to apply their own designed noise reduction devices to practice in life, improve students' STEAM literacy, and enhance students' environmental awareness and social responsibility. The Basic Education Curriculum Reform Outline pointed out: "Chang the curriculum tendency to pay no much attention to the knowledge transfer, emphasize the formation of a proactive learning attitude, so that the process of acquiring basic knowledge and basic skills becomes a process of learning and forming the correct values"[10]. The curriculum based on the STEAM concept is consistent with the goals of the basic education reform, which promotes the comprehensive developments of students' knowledge, skills, learning, and emotions, and improves students' scientific literacy.

This STEAM activity is guided by practical problems in living, is embodied the characteristics of STEAM real problem solving, and is reviewed the students' existing knowledge, and which is the test and the promotion of physics knowledge.As a result, students have been developed in terms of their STEAM knowledge and skills.In terms of methods and skills, the use of data collection, comparison of various materials, the decibel calculations, group's discussions, and the design art demonstrate the interdisciplinary, technical, and engineering nature of STEAM. Students'experimental skills, problem 
solving ability, evidence acquisition, critical thinking, etc. have been developed; In terms of emotional attitudes and values education, students are based on cooperation, expression, and experience. Scientific emotions are also nurtured and cultivated. Therefore, students' emotions, attitudes and values have been developed; In terms of scientific exploration and innovation consciousness education ${ }^{[11]}$.This design advocates students to collect data, raise questions, optimize programs, explore practices, reflect on arguments, express assessments, etc.It effectively enhances students' scientific exploration and innovation capabilities. The activity design based on STEAM education not only meets the requirements of our country's curriculum, but also effectively improves students'examination results and meaningful learning. It will also become a novel scientific teaching design mode.

\section{B. Analysis of experimental results}

The results of the survey show that the STEAM-based physics teaching experiment in junior high school is very successful and effectively improves the STEAM literacy of students. Students have a deep understanding of STEAM knowledge. The reason is that after three months of teaching, everyone understands the relationship between science, technology, mathematics, art, and engineering, and can learn science(physics) knowledge from the activity. At the same time as learning scientific knowledge, consciously linking mathematical formulas and methods, linking engineering practices and living practices, and linking technology applications. Students had not made much progress in the STEM method, which is related to their lack of experience and practice. Students had a very high degree of progress in STEAM emotions, indicating that students like this type of teaching. This is related to students' curiosity and extensive interest. The practicality of the experiment was outstanding, and there were no strict requirements and assessments in the process. Students were also active in the STEAM concepts, which is highlighted by the fact that students had many ideas and changes in this area. Students use physics knowledge to promote, investigate, etc., it can affect parents, communities, and other people around. Students' progress in STEAM thinking was general, indicating that the cultivation of thinking needs to be strengthened. This was related to the short experimental time, single teacher, and limited materials. The reason is that the cultivation of thinking needs special teaching and an outstanding way to carry on. The progress of students in STEAM capabilities was also small. The reason is that students were constantly learning and digging in this area, students' ability, lack of experience, and so on.

From the first topic of the questionnaire, students with good physics learning performance had outstanding performance in all aspects of STEAM literacy, indicating that the survey of STEAM literacy and the implementation of STEAM teaching were in line with teaching practice. At the same time, it shows that students had better control over their personality characteristics.

Judging from the students' self-assessment results, most of the students were satisfied with their performance in this teaching practice. Although some students were not particularly positive about their performance in the classroom, but they were generally good. The results of inter-group mutual evaluation fully demonstrated the wisdom and the style of each group member and the degree of cooperation among the members of the group. At the same time, the process of inter-group mutual evaluation was also a process in which different groups learn from each other. In the process, Students' participation and enthusiasm were very high. Teachers only need to conduct timely and reasonable guidance. It can thus be seen that the implementation of the physics teaching design in junior high school under the STEM education concept truly reflects the teaching concepts of the new curriculum.

Regarding teachers' evaluation, it mainly focused on some key elements in the design and production of experimental devices, from the four dimensions of text and picture design, division of labor cooperation, display instructions, and equipment arrangement. Comprehensive examination of students' ability to explore, hands-on ability, oral expression ability, cooperation spirit, environmental protection concepts. The teacher's evaluation was not only an affirmation of the student's learning process, but also an affirmation of the student's basic literacy and personality. For example, although the performance of individual teams in the process of reporting on results was average, they actively create a harmonious atmosphere for discussion in the process of group cooperation, and they can consciously integrate experimental instruments after the event. And clean up the corners of the event, so the final score was also higher. Based on this, the method of selecting teachers' evaluations can promote the overall development of students.

\section{CONCLUSION}

The STEAM Literacy questionnaire designed in this study had reasonable reliability and validity, and can be used to measure students' STEAM literacy.

The STEAM teaching cases designed in this work can reflect the integration of STEAM education concepts and junior high school physics teaching from five aspects: science(S), technology(T), engineering(E), art(A)and mathematics(M). The "noise reduce produce" teaching with "6E" design learning process is a very good case in physics curriculum at the junior high school.

According to the teaching of STEAM education, the students' understanding of STEAM in the three dimensions of knowledge, emotion, and concept had been significantly improved, with a percentage increase of about 55\%. And there were also improvement in the three dimensions of method, thinking, and ability,however, there was a significant difference.

\section{REFERENCES}

[1] Ministry of Education of the People's Republic of China. Compulsory Education Physics Curriculum Standard(2011 Edition)[M]. Beijing: Beijing Normal University Publishing House. January 2012:28.(In Chinese)

[2] Ling-ling Wang . Research on Primary School Science Curriculum Design Based on STEM[D].East China Normal University, 2015.(In Chinese) 
[3] Rhend a Christensen. GeraldKnezek. TandraTyler-Wood.Science of Science, Technology, Engineering and Mathematics[J]. Computers in Human Behavior.Volum34, May 2014, 173-186.

[4] TJ Moore, KA Smith. Advance the state of the art of STEM Foundation[J].Journal of STEM Education, 2014, 15(1), 5-10.

[5] Barry, N. The ITEEA 6E emerging by DeSIGNTMModel[J].Technology Engineering Technology. 2014, 73:14 $-19$.

[6] Chih-Chao Chung, Chien-Linag Lin, and Shi-JerLou.Analysis of the Special Course of the STEAM-6E Special Course-A Case Study about the Creative Division of the Society[J].Sustainability 2018, 10, 3040:1 -16 .

[7] N. Khaeroningtyas, A. Permanasari, I. Hamida..STEM learning in material of temperature and its change to improve scientific literacy of junior high school syudents[J]. JurnalPendidikan IPA India (2016) 5(1) 94-100.

[8] Chun-hai Zhang, Haiyan Ye. Integration and Symbiosis: Progress and Exhibition of STEM Education in China[J]. Contemporary education and culture. May 2019 Vol. 11 No. 3: 224-31.(In Chinese)

[9] Qiao-ying Song. The design and practice of chemistry teaching in middle school based on the idea of STEM education-Take making a mirror as an example. Min Nan Normal University:2018.(In Chinese)

[10] Bo-qin Liao. Interpretation of the Physical Curriculum Standard for Compulsory Education(2011 Edition)[M]. Beijing: Higher Education Press, March, 2012: 77.(In Chinese)

[11] Wen-faYan, Jin Lu, Pujun Jin. STEAM activity design based on 6E design learning model-Take bronze artifacts rust removal as an example[J].Chemistry teaching. 2018 Issue 11: 61-65.(In Chinese). 